\title{
PENGEMBANGAN MEDIA PEMBELAJARAN IPA DENGAN ANIMASI MACROMEDIA FLASH BERBASIS MODEL PENGAJARAN LANGSUNG (DIRECT INSTRUCTION) DI SEKOLAH DASAR
}

\author{
Naniek Kusumawati \\ Prodi PGSD FIP IKIP PGRI Madiun \\ naniekkusumawati@gmail.com
}

\begin{abstract}
This research is the development of instructional media developed macromedia flash animation-based teaching model directly in SDN Mangkujayan II Ponorogo. Based on the research got enthusiastic excellent student this is evidenced by the results of the data questionnaire responses following students on learning to use media such as macromedia flash animation, developed the data obtained by 36 students (100\%) expressed interest. Data questionnaire responses of students to the language used in textbooks and media animation data obtained by 32 students (88.9\%) expressed understandable and 4 students (11.1\%) said it was difficult to understand. Data questionnaire responses of students to the illustrations in textbooks and media animation data obtained by 35 students (97.2\%) expressed delight and 1 student (2.7\%) were not happy. Mastery of student learning outcomes after the use of instructional media macromedia flash animation-based teaching model directly based on analysis of data on student learning outcomes results obtained by 28 students completed the individual, the individual is not finished 8 students from 36 students who take the post-test. Mastery of cognitive learning outcomes for students in classical $77.78 \%$. This means that students of class $V$ have achieved mastery of learning outcomes are classical.
\end{abstract}

Keyword: Macromedia Flash Animation, Models Direct Insteraction, Ccompleteness Learning Outcomes

\begin{abstract}
Abstrak
Penelitian ini merupakan penelitian pengembangan yaitu mengembangkan media pembelajaran animasi macromedia flash berbasis model pengajaran langsung di SDN Mangkujayan II Ponorogo. Berdasarkan hasil penelitian yang telah dilakukan mendapat antusias yang sangat baik oleh siswa hal ini dibuktikan dengan hasil data angket respon siswa pada pembelajaran berikutnya menggunakan media animasi macromedia flash seperti yang dikembangkan diperoleh data sebanyak 36 siswa $(100 \%)$ menyatakan berminat. Data angket respon siswa terhadap bahasa yang digunakan dalam buku ajar dan media animasi diperoleh data sebanyak 32 siswa $(88,9 \%)$ menyatakan mudah dipahami dan 4 siswa $(11,1 \%)$ menyatakan sulit dipahami. Data angket respon siswa terhadap ilustrasi dalam buku ajar dan media animasi diperoleh data sebanyak 35 siswa $(97,2 \%)$ menyatakan senang dan 1 siswa $(2,7 \%)$ menyatakan tidak senang. Ketuntasan hasil belajar siswa setelah menggunakan media pembelajaran animasi macromedia flash berbasis model pengajaran langsung berdasarkan analisis data
\end{abstract}


terhadap hasil belajar siswa diperoleh hasil sebanyak 28 siswa tuntas individu, 8 siswa tidak tuntas individu dari 36 siswa yang mengikuti post-test. Ketuntasan hasil belajar kognitif siswa secara classical sebesar 77,78\%. Hal ini berarti siswa kelas V telah mencapai ketuntasan hasil belajar secara classical.

Kata Kunci : Animasi Macromedia Flash, Model Pengajaran Langsung (Direct Instruction), Ketuntasan Hasil Belajar

\section{A. Pendahuluan}

Salah satu aspek pembelajaran Ilmu Pengetahuan Alam (IPA) yang sering mendapat sorotan dari berbagai kalangan dewasa ini adalah strategi belajar mengajar. Hal ini terlihat dengan adanya kritikan maupun upayaupaya konstruktif dari pihak tertentu untuk mengusahakan pengembangan strategi tersebut agar siswa lebih menguasai dan dapat mengaplikasikan konsepkonsep IPA dalam kehidupan sehari-hari.

Materi IPA di Sekolah Dasar (SD) konsep dasarnya merupakan generalisasi yang ditarik dari fenomena alam kemudian diakumulasikan dalam bentuk teori atau rumus. Salah satu permasalahan yang terdapat dalam proses pembelajaran IPA saat ini adalah lemahnya proses pembelajaran. Proses pembelajaran di dalam kelas lebih banyak diarahkan kepada siswa untuk menghafal informasi tanpa dituntut untuk memahami dan mengembangkan informasi yang diingat dalam kehidupan seharihari. Permasalahan tersebut dikarenakan guru kurang memanfaatkan penggunaan media pembelajaran pada saat pembelajaran (Susilana dan Riyana, 2007:3).

Hakikat dari proses belajar mengajar adalah proses komunikasi yaitu penyampaian informasi dari sumber informasi melalui media tertentu kepada penerima informasi. Kelemahan proses pembelajaran dapat dikarenakan adanya berbagai jenis hambatan dalam proses komunikasi antara siswa dan guru karena variasi dalam pengajaran serta jarangnya penggunaan alat bantu/media pembelajaran yang dapat memperjelas gambaran siswa tentang materi yang dipelajari (Merduati, 2010: 3).

Berdasarkan hasil observasi dan wawancara dengan guru SDN Mangkujayan II Ponorogo, proses pembelajaran masih menggunakan buku paket yang bersifat informatif sehingga siswa belum mampu mengembangkan pengetahuan yang dimilikinya. Selain itu guru sering menggunakan LKS yang diambil dari luar buku panduan antara lain dari buku kumpulan LKS. Struktur dan isi LKS masih bersifat monoton, yakni konsep materi kurang dan soalsoal latihan terlalu sulit. Bahan ajar umumnya masih bersifat informatif sehingga belum mewujudkan lingkungan yang memungkinkan siswa untuk mengembangkan kemampuan 
berfikirnya sendiri, seperti buku panduan yang cenderung kurang kontekstual dan bahasanya sulit dipahami oleh siswa.

Salah satu yang dapat dilakukan untuk mengatasi permasalahan yaitu dengan mengembangkan suatu media pembelajaran IPA berbasis Macromedia Flash yang dapat digunakan siswa selama proses pembelajaran. Media pembelajaran adalah alat, metode, dan teknik yang digunakan dalam rangka lebih mengaktifkan komunikasi dan interaksi antara guru dan siswa dalam proses pendidikan dan pembelajaran di sekolah (Hamalik, 1991:2). Menurut Ruseffendi (dalam Madeamin, 2003), media merupakan semua bentuk perantara yang dipakai orang sebagai penyebar ide sehingga gagasan tersebut sampai kepada penerima. Sementara itu media juga merupakan saluran (channel) yang dapat memperluas kemampuan manusia untuk melihat, mendengar, merasakan, yang semula sangat terbatas. Animasi multimedia dapat membantu siswa dalam memahami materi pembelajaran yang diberikan dan mampu meningkatkan pengalaman belajar siswa. Animasi merupakan kolaborasi yang harmonis antara seni dan teknologi. Animasi macromedia flash merupakan kumpulan gambar yang diolah sedemikian rupa sehingga menghasilkan gerakan. Keunggulan Animasi dalam pembelajaran yakni, didukung dengan dasar medianya yang berawal dari gambar dan kartun membuat animasi memiliki beberapa keunggulan, terutama dalam bagaimana animasi bisa dengan mudah diterima oleh beragam kalangan masyarakat dan kemampuannya untuk survival, bertahan untuk berada di dalam pikiran kita dalam jangka waktu yang sangat lama (Hafiz, 2008:2).

Penggunaan media pembelajaran berbasis animasi macromedia flash akan dapat berjalan lebih optimal apabila guru mampu menggunakan model pembelajaran dengan baik. Salah satu model pembelajaran yang dapat digunakan guru adalah model pengajaran langsung (direct instruction). Model pengajaran langsung (direct instruction) adalah salah satu pendekatan mengajar yang dirancang khusus untuk menunjang proses belajar siswa yang berkaitan dengan pengetahuan deklaratif dan pengetahuan prosedural yang terstruktur dengan baik yang dapat diajarkan dengan pola kegiatan yang bertahap, selangkah demi selangkah. Selain itu model pengajaran langsung ditujukan pula untuk membantu siswa mempelajari keterampilan dasar dan memperoleh informasi yang dapat diajarkan selangkah demi selangkah (Trianto, 2010:44).

Menurut Kardi dan Nur dalam Trianto (2010:45), Ciri-ciri model pengajaran langsung adalah sebagai berikut: (1) Adanya tujuan pembelajaran dan pengaruh model pada siswa 
termasuk prosedur penilaian; (2) Sintaks atau pola keseluruhan dan alur kegiatan pembelajaran; (3) Sistem pengelolaan dan lingkungan belajar model yang diperlukan agar kegiatan pembelajaran tertentu dapat berlangsung dengan berhasil. Pengajaran langsung menurut Karti dalam Trianto (2010:45), dapat berbentuk ceramah, demonstrasi, pelatihan atau praktik, diskusi, dan kerja kelompok. Dari deskripsi di atas dapat disimpulkan bahwa peneliti perlu mengembangkan suatu media pembelajaran berbasis Macromedia Flash dengan model pengajaran langsung (Direct Instruction) pada mata pelajaran IPA fisika pokok bahasan cahaya sehingga diharapkan akan mampu meningkatkan pemahaman, kreatifitas siswa, dan keaktifan siswa yang pada akhirnya dapat meningkatkan kualitas pembelajaran yang berdampak pada kualitas out put yang dihasilkan.

\section{B. Metode}

Penelitian ini termasuk penelitian pengembangan (Developmental Research), karena mengembangkan suatu media pembelajaran berbasis Macromedia Flash dengan model pengajaran langsung (Direct Instruction), RPP, lembar kerja siswa, angket respon siswa terhadap kegiatan pembelajaran, lembar pengamatan aktivitas siswa, kendala-kendala yang ditemui selama penelitian, dan instrumen validasi perangkat pembelajaran. Subjek penelitian dilakukan pada siswa kelas $\mathrm{V}$ di SDN Mangkujayan II Ponorogo dengan materi IPA fisika pokok bahasan cahaya.

Rancangan pembelajaran perangkat pembelajaran ini mengadaptasi modifikasi model pengembangan 4-D yang dikembangkan oleh Thiagarajan (dalam Trianto, 2010:189). Pada penelitian ini tahapan penyebaran tidak dilaksanakan karena keterbatasan waktu dan dana yang dimiliki peneliti. Uji pengembangan dilaksanakan pada satu yang telah ditentukan. Kegiatan ini bertujuan untuk mengumpulkan data-data yang terkait dengan uji pengembangan antara lain: data tentang keterlaksanaan rencana pembelajaran, ketuntasan hasil belajar siswa, dan respon siswa terhadap media pembelajaran berbasis animasi (Macromedia Flash) dengan model pengajaran langsung (Direct Instruction) untuk siswa. Rancangan kegiatan uji pengembangan dilaksanakan dengan teknik one shoot case study seperti gambar dibawah ini:

$$
\mathbf{X} \longrightarrow \mathbf{O}
$$

Gambar 3.3 Rancangan uji pengembangan

Keterangan:

$\mathrm{X}$ : Pembelajaran dengan menggunakan modul pembelajaran fisika

O : Post-test (Sugiyono, 2008:64)

Data validasi dianalisis secara deskriptif penentuan analisis rata-rata 
berdasarkan pada Arikunto (2002:216) yang menyatakan bahwa untuk mengetahui peringkat nilai akhir pada setiap butir angket penelitian, jumlah nilai yang diperoleh dibagi dengan banyaknya responden yang menjawab angket penilaian tersebut. Rumusan perhitungan nilai rata-rata sebagi berikut:

$$
\bar{x}=\frac{\Sigma x}{n}
$$

Keterangan:

$\bar{X}=$ nilai rata-rata

$\Sigma x=$ jumlah skor jawaban

$$
\text { penilaian }
$$

$\mathrm{n}=$ jumlah responden (validator)

Skala penilaian yang digunakan pada penelitian ini adalah 1 sampai 3 , dimana 1 sebagai nilai terendah dan 3 sebagai nilai tertinggi. Penentuan rentang nilai yaitu dengan cara nilai tertinggi dikurangi nilai terendah dibagi dengan nilai tertinggi.

Observasi keterlaksanaan pembelajaran digunakan untuk mengetahui tingkat keterlaksanaan program yang dilaksanakan oleh guru pada saat kegiatan pembelajaran. Keterlaksanaan RPP berisi langkah-langkah yang harus dilakukan guru, skor yang harus diberikan pengamat berdasarkan petunjuk penilaian yang ada dan saran pengamat. Reabilitas pengamatan keterlaksanan RPP ini di uji dengan rumus sebagai berikut;

Percentage of agreement $=100 \%$

$$
\left(1-\frac{A-z}{\Delta+2}\right)
$$

keterangan:

$\mathrm{A}=$ frekuensi aspek tingkah laku yang teramati oleh pengamat yang memberikan frekuensi tinggi.

$\mathrm{B}=$ frekuensi aspek tingkah laku yang teramati oleh pengamat yang memberikan frekuensi rendah.

Instrumen dikatakan baik jika mempunyai koefisien reliabilitas $\geq$ 0,75 atau $\geq 75 \%$.

(Borich dalam Trianto, 2010:240). Untuk menentukan ketuntasan hasil belajar siswa (clasical) dapat dihitung dengan menggunakan persamaan sebagai berikut:

$$
\mathrm{KB}=\frac{\tau}{z_{\mathrm{c}}} \times 100 \%
$$

keterangan:

$\mathrm{KB}=$ ketuntasan belajar clasical

$\mathrm{T}=$ jumlah siswa yang tuntas

$\mathrm{Tt}=$ jumlah siswa

Angket respon siswa digunakan untuk mengukur pendapat siswa terhadap media pembelajaran berbasis animasi macromedia flash dengan model pengajaran langsung. Angket respons siswa diberikan pada siswa setelah menyelesaikan seluruh kegiatan pembelajaran.

Persentase respons siswa dihitung dengan menggunakan rumus:

Percentage of agreement $=\frac{A}{B} \times 100 \%$ keterangan:

$\mathrm{A}=$ proporsi jumlah siswa yang memilih $\mathrm{B}=$ jumlah siswa (Trianto, 2010:243). 


\section{Hasil dan Pembahasan}

Tujuan dalam penelitian ini adalah mengembangkan media pembelajaran berbasis macromedia flash dengan model pengajaran langsung di SDN Mangkujayan II Ponorogo, aktivitas siswa dalam kegiatan belajar mengajar, dan ketuntasan hasil belajar siswa. Data keterlaksanakan pembelajaran menunjukkan reliabilitas instrument pengamatan keterlaksanaan pembelajaran dan kesimpulan penilaian observer terhadap keterlaksanaan dari RPP dapat dilihat pada tabel 1 .

Tabel. 1 Data keterlaksanaan pembelajaran

\begin{tabular}{|c|c|c|c|c|c|c|}
\hline $\mathrm{N}$ & \multirow{2}{*}{ RPP } & \multicolumn{2}{|c|}{ Observer } & \multirow{2}{*}{ Rata-rata } & \multirow{2}{*}{ Kate gori } & \multirow{2}{*}{ Reabi litas } \\
\hline No & & $\mathrm{O} 1$ & $\mathrm{O} 2$ & & & \\
\hline \multirow[t]{4}{*}{1} & RPP_01 & & & & & \multirow{4}{*}{$96,55 \%$} \\
\hline & a. Pendahuluan & 3 & 3 & 3 & \multirow{3}{*}{ Baik } & \\
\hline & b. Bagian isi & 2,6 & 3 & 2,8 & & \\
\hline & c. Penutup & 3 & 3 & 3 & & \\
\hline \multirow[t]{4}{*}{2} & RPP_02 & & & & \multirow{4}{*}{ Baik } & \multirow{4}{*}{$96 \%$} \\
\hline & d. Pendahuluan & 3 & 3 & 3 & & \\
\hline & a. Bagian isi & 2,4 & 2,9 & 2,65 & & \\
\hline & b. Penutup & 3 & 3 & 3 & & \\
\hline \multirow[t]{4}{*}{3} & RPP_03 & & & & \multirow{4}{*}{ Baik } & \multirow{4}{*}{$96 \%$} \\
\hline & e. Pendahuluan & 3 & 3 & 3 & & \\
\hline & a. Bagian isi & 2,6 & 2,9 & 2,8 & & \\
\hline & b. penutup & 3 & 3 & 3 & & \\
\hline \multirow{3}{*}{\multicolumn{3}{|c|}{$\begin{array}{l}\text { Data respon siswa terhadap } \\
\text { media pembelajaran macromedia } \\
\text { flash pada pembelajaran IPA fisika }\end{array}$}} & \multicolumn{2}{|c|}{ angket respon } & \multicolumn{2}{|c|}{ kepada siswa setelah } \\
\hline & & & & elesaikan & seluruh & kegiatan \\
\hline & & & & elajan. D & ta respon & siswa dapat \\
\hline dipe & Dleh dengan & rikan & & & & bel. \\
\hline
\end{tabular}

Tabel. 2 Data angket respon siswa

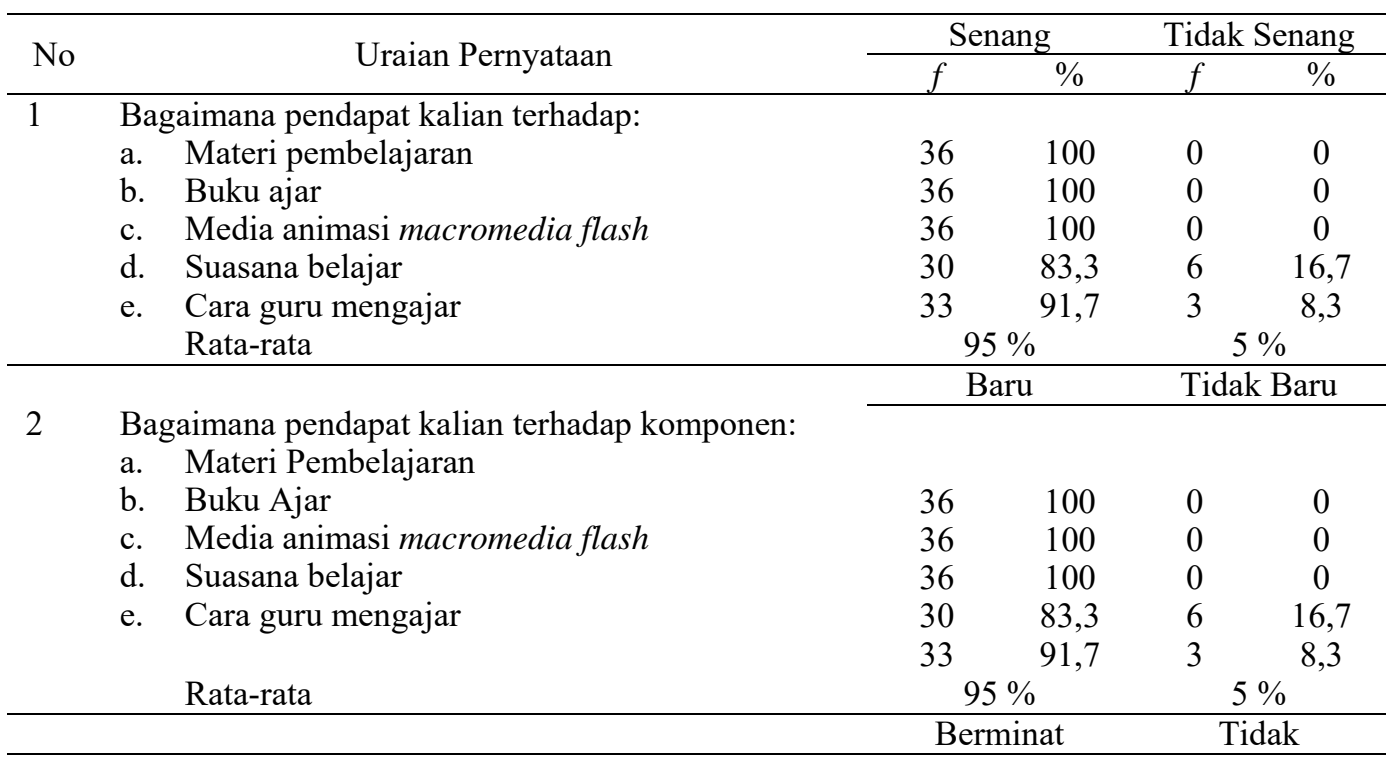




\begin{tabular}{|c|c|c|c|c|c|}
\hline \multirow[t]{2}{*}{3} & \multirow{2}{*}{$\begin{array}{l}\text { Proses belajar berikutnya menggunakan } \\
\text { pembelajaran seperti ini }\end{array}$} & \multicolumn{4}{|c|}{ Berminat } \\
\hline & & 36 & 100 & 0 & 0 \\
\hline \multirow[b]{2}{*}{4} & \multirow[b]{2}{*}{$\begin{array}{l}\text { Bahasa yang digunakan dalam buku ajar dan media } \\
\text { animasi macromedia flash }\end{array}$} & \multicolumn{2}{|c|}{ Mudah } & \multicolumn{2}{|c|}{ Sulit } \\
\hline & & 32 & 88,9 & 4 & 11,1 \\
\hline \multirow[b]{2}{*}{5} & \multirow[b]{2}{*}{$\begin{array}{l}\text { Ilustrasi yang terdapat dalam buku ajar dan media } \\
\text { animasi macromedia flash }\end{array}$} & \multicolumn{2}{|c|}{ Senang } & \multicolumn{2}{|c|}{ Tidak Senang } \\
\hline & & 35 & 97,2 & 1 & 7,8 \\
\hline
\end{tabular}

$f=$ frekuensi

Analisis data ketuntasan hasil belajar IPA fisika siswa didasarkan pada hasil post-test yang dilakukan setelah melaksanakan pembelajaran. Kriteria ketuntasan minimal (KKM) individu yang ditetapkan untuk mata pelajaran IPA fisika kelas V semester genap di SDN Mangkujayan II Ponorogo adalah $\geq 68$, sedangkan KKM clasical terpenuhi apabila terdapat $\geq 75 \%$ siswa yang tuntas. Berdasarkan analisis data terhadap hasil belajar siswa diperoleh hasil sebanyak 28 siswa tuntas individu, 8 siswa tidak tuntas individu dari 36 siswa yang mengikuti post-test. Ketuntasan hasil belajar kognitif siswa secara classical sebesar $77,78 \%$. Hal ini berarti siswa kelas $\mathrm{V}$ telah mencapai ketuntasan hasil belajar secara clasical.

Respon siswa terhadap media pembelajaran IPA fisika yang dikembangkan tergolong positif. Sebagian besar siswa merasa senang mengikuti pembelajaran dengan menggunakan media pembelajaran IPA fisika berbasis animasi macromedia flash karena merupakan suatu hal yang baru dalam proses pembelajaran. Selain itu, media pembelajaran IPA fisika menggunakan animasi macromedia flash selama kegiatan pembelajaran dapat membantu siswa dalam memahami materi pembelajaran yang disajikan dalam buku paket IPA fisika. Dari rekapitulasi data respon siswa pada uji pengembangan diperoleh gambaran bahwa pendapat siswa terhadap media pembelajaran IPA fisika berbasis animasi macromedia flash dengan model pengajaran langsung (direct instruction) tergolong positif.

\section{Kesimpulan dan Saran \\ Kesimpulan}

Berdasarkan data yang diperoleh pada tahap pengembangan, analisis data dan pembahasan yang telah diuraikan pada bab sebelumnya, maka dapat diambil kesimpulan sebagai berikut.

1. Kualitas Perangkat Pembelajaran IPA fisika

Pengembangan media pembelajaran IPA fisika berbasis animasi macromedia flash dengan model pengajaran langsung (direct instruction) pokok bahasan cahaya. Perangkat pembelajaran IPA fisika yang telah divalidasi terdiri atas silabus pembelajaran, rencana 
pelaksanaan pembelajaran (RPP), buku ajar dan soal evaluasi. Hasil validasi ahli mendapatkan kesimpulan bahwa silabus pembelajaran berkategori baik, rencana pelaksanaan pembelajaran (RPP) berkategori baik, buku ajar berkategori baik, dan soal evaluasi barkategori valid.

2. Keterlaksanaan Pembelajaran

Keterlaksanaan

pembelajaran berdasarkan penilaian observer telah terlaksana dengan baik. Dalam hal ini berarti guru (peneliti) telah melaksanakan pembelajaran sesuai dengan rencana pelaksanaan pembelajaran (RPP) yang dikembangkan.

3. Ketuntasan Hasil Belajar Fisika Siswa

Ketuntasan hasil belajar kognitif siswa SDN Mangkujayan II Ponorogo yaitu sebanyak 28 tuntas individu dan 8 siswa tidak tuntas individu setelah melaksanakan pembelajaran. Ketuntasan hasil belajar kognitif siswa secara clasical sebesar 77,78\%. Bedasarkan data tersebut dapat disimpulkan bahwa kelas $\mathrm{V}$ telah mencapai ketuntasan secara classical.

4. Respon Belajar Siswa Terhadap Animasi Macromedia Flash

\begin{abstract}
Siswa kelas V SDN Mangkujayan II Ponorogo memberikan respon positif terhadap penggunaan media pembelajaran berbasis macromedia flash untuk siswa pada pokok bahasan cahaya. Siswa menginginkan pembelajaran menggunakan media pembelajaran animasi macromedia flash pokok bahasan cahaya yang telah dilaksanakan juga dilaksanakan pada pembelajaran selanjutnya.
\end{abstract}

\section{Saran}

Berdasarkan hasil pengembangan dan penelitian yang telah dilakuka, maka saran yang dapat diajukan adalah:

a. Pengembangan media pembelajaran IPA fisika dapat dilengkapi dengan kegiatan keterampilan proses untuk siswa.

b. Pada saat uji pengembangan, peralatan pembelajaran perlu dipersiapkan dengan sebaik-baiknya agar pada saat pembelajaran tidak terjadi suatu hal yang dapat menggangu pelaksanaan pembelajaran.

c. Bagi peneliti lanjut, sebaiknya penelitian pengembangan ini juga dilakukan pada materi yang lain karena banyak materi IPA fisika yang dapat dikembangkan dalam bentuk media pembelajaran IPA fisika berbasis animasi macromedia flash dengan model pengajaran langsung (direct instruction). 


\section{Daftar Pustaka}

Arikunto, S. 2002. Prosedur Penelitian Suatu Pendekatan Praktek. Jakarta: Rineka Cipta. Hafiz, A. (2008, Maret 6). Animations Comics Film Production Post Productions Potensi Kartun dan Animasi. Retrieved September 2008, from veegraph.com.

Depdiknas. 2007. Peraturan Mendiknas Nomor: 22 Tahun 2007 tentang Standar Penilaian Pendidikan. Jakarta: Depdiknas.

Hafiz, A. (2008, Maret 6). Animations Comics Film Production Post Productions Potensi Kartun dan Animasi. Retrieved September 2008, from veegraph.com.
Hamalik, Oemar. 1991. Komputerisasi Pendidikan Nasional. Jakarta: CV Mandar Maju

Merduati, N. 2010. Penerapan Modul Pembelajaran Pencemaran Lingkungan dengan Model Siklus Belajar 4E (The 4E Learning Cycle) untuk Meningkatkan Motivasi dan Hasil Belajar Siswa Kelas X MAN Malang I (Tesis). Tidak diterbitkan.

Sugiyono. 2008. Metode Penelitian Pendidikan Kuantitatif, Kualitatif, dan R\&D. Bandung: Alfabeta

Susilana, R., dan Riyana, C. 2007. Media Pembelajaran:Hakikat, Pengembangan, Pemanfaatan, dan Penilaian. Bandung: Wacana Prima.

Trianto. 2010. Mendesain i Pembelajaran Inovatif-Progresif. Jakarta: Kencana. 